\title{
Physico-Chemical Properties of Zn-Ni Alloy Deposits from an Acid Sulphate Bath Containing Ethanolamines
}

\author{
V. Narasimhamurthy1,*, L.H. Shivashankarappa ${ }^{2}$ \\ ${ }^{1}$ Government First Grade College and Post Graduate Study Center, Shivamogga - 577 201, Karnataka, India. \\ ${ }^{2}$ Maharani Science College for Women, Palace Road, Bengaluru - 560 001, Karnataka, India.
}

\section{ARTICLE DETAILS}

Article history:

Received 07 September 2020

Accepted 20 September 2020

Available online 28 September 2020

\section{Keywords:}

Ethanolamines

Zn-Ni Alloy

Current Density

Cathodic Current Efficiency

\begin{abstract}
A B S T R A C T
The composition, properties, structure and morphology of electrodeposited Zn-Ni alloy deposits obtained from an acid sulphate bath have been investigated. A bath having higher percentage of nickel (50\%) produced an alloy deposit with low percentage of nickel (12\%), the percentage of nickel in the alloy deposit increases with current density up to $40 \mathrm{~A} \cdot \mathrm{dm}^{-2}$, with further increase in current density, the percentage of nickel shows a downward trend, increase in temperature of the plating bath increases the percentage of nickel in the alloy deposit. The hardness of the alloy deposits increases with increase in nickel content in the alloy, the phase structure of alloy deposit shows the presence of $\alpha, \eta, \delta$ and $\gamma$ phases. The morphology of $\mathrm{Zn}-\mathrm{Ni}$ alloy deposits shows uniform and finer grained structure.
\end{abstract}

\section{Introduction}

Electrodeposited zinc alloys find an extensive use as a viable substitute for zinc and cadmium metals in the corrosion protection of steel. Among zinc alloys, Zn-Ni alloy containing $10-15 \%$ Ni showed high degree of corrosion resistance and mechanical properties. The electrodeposition of $\mathrm{Zn}-\mathrm{Ni}$ alloy is of anomalous co-deposition type as proposed by Brenner [1], i.e. under most conditions, less noble metal (zinc) deposits preferentially than more noble metal (nickel). The $\mathrm{Zn}-\mathrm{Ni}$ alloys have been deposited from various types of baths like sulphate [2-5], sulphamate [6, 7], chloride [8, 9], sulphate-chloride [10], pyrophosphate [11], ammonical [12] and noncyanide baths [13-17].

Many studies have been carried out to understand the characteristics of the deposition process of $\mathrm{Zn}-\mathrm{Ni}$ alloy. It is found that the characteristics of the deposited alloy coating depend on the current density, pH, bath composition, additives and temperature etc., Zinc-Nickel alloy deposition from a complex bath containing more than one organic additive has led to the production of alloy with a low percentage of nickel. Nitrogen containing organic compounds, especially amines is used in plating baths for $\mathrm{Zn}$-Ni alloy deposition. Review of the literature reveals the absence of comprehensive work on the electrodeposition of $\mathrm{Zn}-\mathrm{Ni}$ alloy from acid sulphate bath containing ethanolamines.

The purpose of the present investigation is to develop the optimum plating bath with suitable composition and plating conditions for obtaining good quality $\mathrm{Zn}-\mathrm{Ni}$ alloy deposit with $10-15 \% \mathrm{Ni}$ and to study properties, structure and morphology of $\mathrm{Zn}-\mathrm{Ni}$ alloy deposit.

\section{Experimental Methods}

The plating bath solution was prepared using distilled water and laboratory grade chemicals. The bath solution was purified as described earlier [18]. The optimum bath composition and plating conditions used in the present study are given in Table 1. Electrodeposition was carried out galvanostatically from $250 \mathrm{~mL}$ bath solution by using $1 \mathrm{~cm}^{2}$ stainless steel as cathode and $2 \mathrm{~cm}^{2}$ zinc as anode at $328 \mathrm{~K}$ under stirred conditions. The panel so plated was weighted and stripped in $20 \% \mathrm{HNO}_{3}$, made up to $100 \mathrm{~mL}$ in a standard flask, the zinc and nickel contents in the test solution was analyzed by atomic adsorption spectrometry.

*Corresponding Author:drvnm123@gmail.com(V. Narasimhamurthy)
Table 1 Optimum bath composition and plating conditions for electrodeposition of Zn-Ni alloy containing $10-15 \% \mathrm{Ni}$

\begin{tabular}{ll}
\hline Bath component & Optimum composition \& conditions \\
\hline Total metal content & $0.2 \mathrm{M}$ \\
$\mathrm{ZnSO}_{4} \cdot 7 \mathrm{H}_{2} \mathrm{O}$ & $0.1 \mathrm{M}$ \\
$\mathrm{NiSO}_{4} 7 \mathrm{H}_{2} \mathrm{O}$ & $0.1 \mathrm{M}$ \\
Triethanolamine /Diethanolamine / & $0.1 \mathrm{M}$ \\
Monoethanolamine & \\
Saccharin & $2 \mathrm{~g} / \mathrm{L}$ \\
{$\left[\mathrm{NH}_{4}\right]_{2} \mathrm{SO}_{4}$} & $40 \mathrm{~g} / \mathrm{L}$ \\
$\mathrm{H}_{3} \mathrm{BO}_{3}$ & $30 \mathrm{~g} / \mathrm{L}$ \\
Sodium laurylsulphate & $0.2 \mathrm{~g} / \mathrm{L}$ \\
Temperature & $55{ }^{\circ} \mathrm{C}$ \\
pH & 5.5 \\
Current density & $10 \mathrm{~A} \cdot \mathrm{dm}^{-2}$ \\
Stirring & normal
\end{tabular}

The adhesion of the alloy deposits to the base metal (steel) was tested by a standard bending test. The porosity of the alloy deposit was determined by the Ferroxyl test. The micro-hardness of the alloy deposits was determined on Vickers scale. Deposition potentials of zinc, nickel and $\mathrm{Zn}-\mathrm{Fe}$ alloy deposits dipped in $3.5 \% \mathrm{NaCl}$ were measured with respect to SCE by using scanning potentionstat. The phase structure of the $\mathrm{Zn}-\mathrm{Ni}$ alloy deposits was examined by X-ray powder diffraction (Filter $\mathrm{CuK}_{\alpha \mathrm{l}}, 30$ $\mathrm{kV}, 20 \mathrm{~mA}, 4000$ counts). The surface morphology of the alloy deposits was examined under Scanning electron microscope (Model JEOL-JSM-840A).

\section{Results and Discussion}

\subsection{Composition}

Fig. 1 shows the cathodic polarization curves for $\mathrm{Zn}-\mathrm{Ni}$ alloy deposition as well as individual metal deposition. Curve 1 is the current density potential curve for deposition of $\mathrm{Ni}$ alone, the deposition potential of nickel was around $-0.84 \mathrm{~V}$. Curve 2 is for zinc deposition alone, the deposition potential of zinc was around $-1.03 \mathrm{~V}$ and Curve 3 is for $\mathrm{Zn}-\mathrm{Ni}$ alloy deposition from the same bath solution. The deposition potential of alloy was around-1.15 V. The position of potential of alloy deposition curve is shown to be more negative to both nickel and zinc. This clearly indicates the reason for preferential deposition of zinc i.e. anomalous co-deposition. 


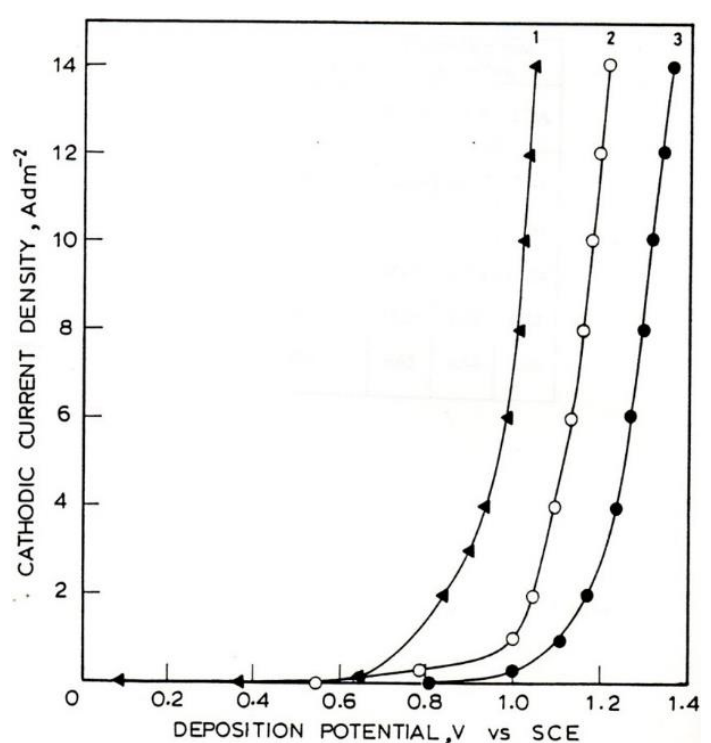

Fig. 1 Cathodic polarization curves for the deposition of nickel, zinc and $\mathrm{Zn}-\mathrm{Ni}$ alloy from an acid sulphate bath. Curve 1. Deposition of nickel; Curve 2. Deposition of zinc; Curve 3. Deposition of alloy.

To study the effect of metal ion ratio in the bath on the alloy composition, zinc to nickel ratio in the bath was varied from 20:80 to 60:40. Fig. 2 shows the variation of alloy composition with bath composition containing fixed concentration of ethanolamines. Under these conditions zinc gets deposited more preferentially than nickel. A bath having higher percentage of nickel (50\%) produced an alloy deposit with low percentage $(12 \%)$ of nickel, it is due to preferential deposition of zinc than nickel (anomalous co-deposition). This is attributed to the formation of zinc hydroxide film at the cathode surface which suppresses the deposition of nickel.

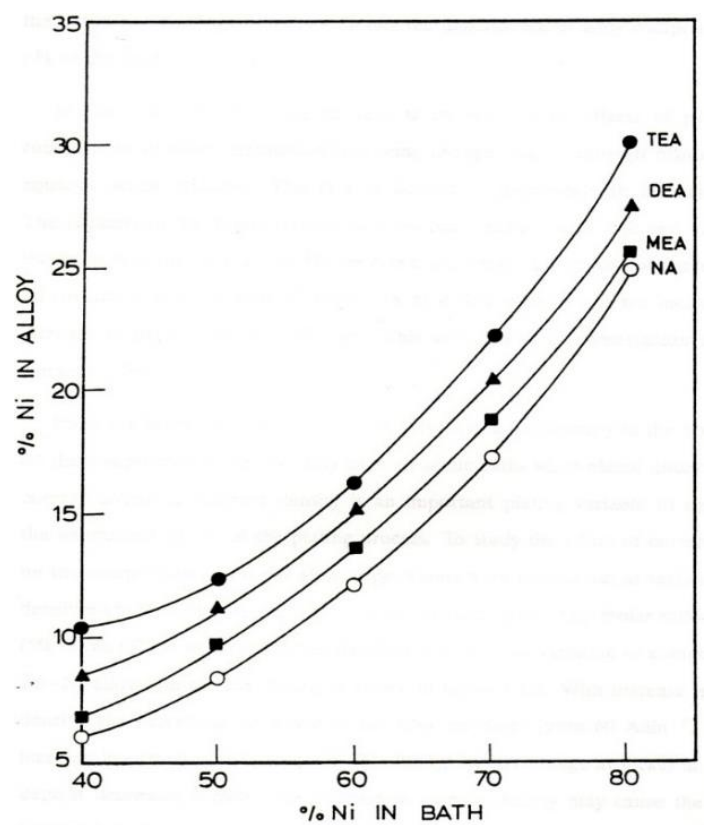

Fig. 2 Dependence of $\% \mathrm{Ni}$ in alloy on the $\% \mathrm{Ni}$ in the bath. Bath composition and operating conditions as in Table $1\left[\mathrm{Zn}^{2+}\right]=0.04-0.12 \mathrm{M}$ and $\left[\mathrm{Ni}^{2+}\right]=0.16-0.08 \mathrm{M}$.

In order to study the effect of current density on the composition of Zn$\mathrm{Ni}$ alloy experiments were carried out at various current densities (5-80 A.dm-2) using bath solutions containing constant molar ratio of $\mathrm{Zn} / \mathrm{Ni}$ $(50 / 50)$ and $0.1 \mathrm{M}$ of mono-, di- and tri-ethanolamines at $328 \mathrm{~K}$. The variation in the composition of the deposited alloy with current density is shown in Fig. 3. The percentage of nickel in the alloy deposit increases with

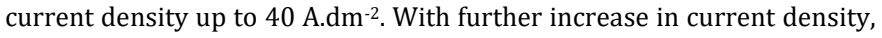
the cathode potential becomes more negative and hence the percentage of nickel shows a downward trend. This decrease in percentage of nickel with increase in current density clearly indicates diffusion-controlled nature of $\mathrm{Zn}-\mathrm{Ni}$ alloy deposition. Increase in temperature of the plating bath increased the percentage of nickel in the alloy deposit. This is probably due to the decrease in the polarization potential of nickel (more noble metal) during alloy deposition.

https://doi.org/10.30799/jaec.060.20060102

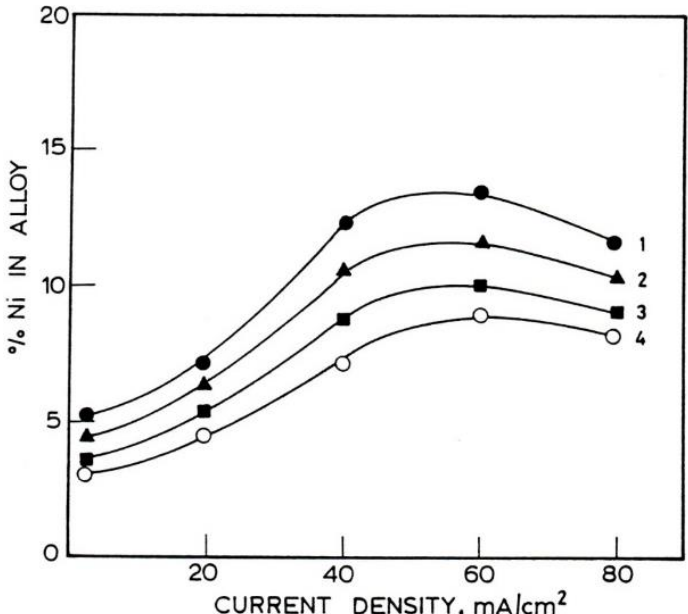

Fig. 3 Dependency of alloy composition on current density. Bath composition and operating conditions as in Table 1. Current density range 2.5-80 A.dm ${ }^{-2}$; Curve 1: TEA; Curve 2: DEA; Curve 3: MEA; Curve 4: NA.

Fig. 4 shows the dependence of the percentage of nickel in the alloy on the concentration of ethanolamines in the bath. The percentage of nickel in the alloy deposit is increased with increase in concentration of ethanolamines, attained a maximum value at $0.2 \mathrm{M}$ and then decreases slightly with further increase in the concentration of ethanolamines $(>0.2$ M). The formation of a loose complex with metal ions always facilitates the deposition process. In the present system, the nickel complex formed with different ethanolamine $(0.2 \mathrm{M})$ used may be active at the cathode, which stimulate the electrochemical discharge of nickel at higher rate. At the concentration $>0.25 \mathrm{M}$, the nickel may form strong complex that may retard the deposition of nickel, which leads to a decrease in the percentage of nickel in the alloy deposit at higher ethanolamine concentration.

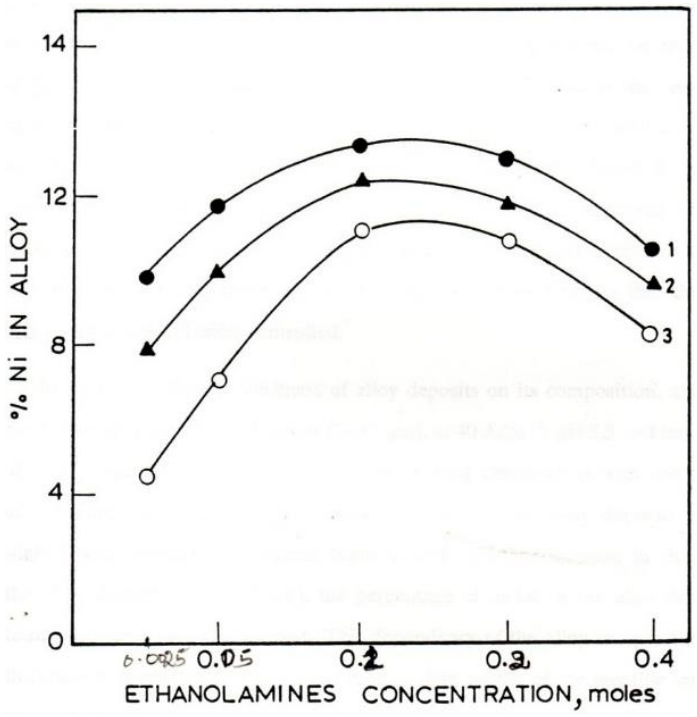

Fig. 4 Dependency of alloy composition on the concentration of ethanolamines. Bath composition and operating conditions as in Table 1; Ethanolamines concentration 0.05-0.4 M; Curve 1: TEA; Curve 2: DEA; Curve 3: MEA; Curve 4: NA.

The effect of stirring on the alloy composition was studied by carrying out experiments under stirred as well as unstirred conditions. The percentage of nickel in the alloy deposit was found to be high under stirred conditions compared to those obtained under unstirred conditions (Table 2). A significant increase in the percentage of nickel in the alloy deposit with stirring of the bath clearly indicates that deposition is under diffusion control.

Table 2 Effect of stirring on CCE

\begin{tabular}{lllll}
\hline Parameter & \multicolumn{4}{l}{ CCE in media containing $0.1 \mathrm{M}$ of } \\
\cline { 2 - 5 } & NA & MEA & DEA & TEA \\
\hline With stirring & 7.51 & 8.52 & 10.50 & 12.33 \\
$\% \mathrm{Ni}$ & 97.89 & 78.07 & 63.26 & 56.11 \\
$\mathrm{CCE}$ & & & & \\
Without Stirring & 6.33 & 7.67 & 9.48 & 11.14 \\
$\% \mathrm{Ni}$ & 88.17 & 73.66 & 60.59 & 54.02 \\
$\mathrm{CCE}$ & & & &
\end{tabular}


The variation of alloy composition with its thickness is studied. The percentage of nickel in the deposit increased up to $4 \mu \mathrm{m}$. With further increase in deposit thickness, the percentage of nickel in the alloy deposit showed a downward trend. Beyond $4 \mu \mathrm{m}$ thickness, the cathode diffusion layer may not supply enough of nickel ions to the cathode surface and hence the decrease in the percentage of nickel in the alloy deposit. The cathodic current efficiencies (CCE) were calculated for the $\mathrm{Zn}-\mathrm{Ni}$ alloy deposition under each set of experimental condition. With increase in current density the CCE increased and attains a steady value. The CCE from bath containing no additives was found to be maximum compared in baths containing ethanolamines. With increase in temperature, CCE increased up to $55^{\circ} \mathrm{C}$, beyond this temperature, the CCE decreased (Table 3).

Table 3 Effect of temperature on CCE

\begin{tabular}{lllll}
\hline Temperature $\left({ }^{\circ} \mathrm{C}\right)$ & \multicolumn{4}{l}{ CCE in media containing } \\
\cline { 2 - 5 } & NA & MEA & DEA & TEA \\
\hline 25 & 19.10 & 17.87 & 15.12 & 9.56 \\
35 & 76.56 & 61.11 & 61.96 & 48.82 \\
55 & 87.89 & 78.07 & 63.26 & 56.11 \\
75 & 71.67 & 58.67 & 52.17 & 52.01 \\
\hline
\end{tabular}

\subsection{Properties}

The adhesion of $\mathrm{Zn}-\mathrm{Ni}$ alloy deposit to the base metal (steel) was tested by a standard bending test. Alloy samples coated to different thickness (2$12 \mu \mathrm{m})$ on steel $(1 \times 4$ sq. inch) were subjected to bending tests. The alloy coatings did not develop any visual cracks even after $180^{\circ}$ bending. This shows a good adhesion of the alloy deposits to be steel surface. Porosity tests were carried out on alloy coated to $2-12 \mu \mathrm{m}$ thickness on steel panels $13 \times 3 \mathrm{sq}$. inch). A filter paper soaked in $1 \%$ potassium ferricyanide solution was placed on alloy coated steel panels. The number of blue spots appearing on the filter paper with time was a measure of porosity of the deposit. The alloy deposits were pore free at thickness $>4 \mu \mathrm{m}$. The microhardness of $\mathrm{Zn}-\mathrm{Ni}$ alloy (10 $\mu \mathrm{m}$ thick deposit) specimens was determined. The hardness of the alloy deposits increased with increase in nickel content in the alloy. The static potential values of zinc and zincnickel alloy were measured with respect to SCE in $3.5 \% \mathrm{NaCl}$ solution. The potentials of $\mathrm{Zn}-\mathrm{Ni}$ alloy were found to be less noble to steel and more noble to zinc. This clearly shows that $\mathrm{Zn}-\mathrm{Ni}$ alloy coatings protect steel more efficiently than zinc coatings (Table 4).

Table 4 Dependency of nickel content in the $\mathrm{Zn}-\mathrm{Ni}$ alloy on microhardness and on static potentials

\begin{tabular}{lll}
\hline \%Ni in alloy & $\begin{array}{l}\text { Microhardness } \\
\text { in VHN (load }-50 \mathrm{~g})\end{array}$ & $\begin{array}{l}\text { Static potential in } \mathrm{mV} \text { vs. SCE } \\
\text { in } 3.5 \% \mathrm{NaCl}\end{array}$ \\
\hline 0 & 120 & -1060 \\
10 & 300 & -1050 \\
15 & 330 & -1043 \\
20 & 370 & -1028 \\
25 & 450 & -1010 \\
\hline
\end{tabular}

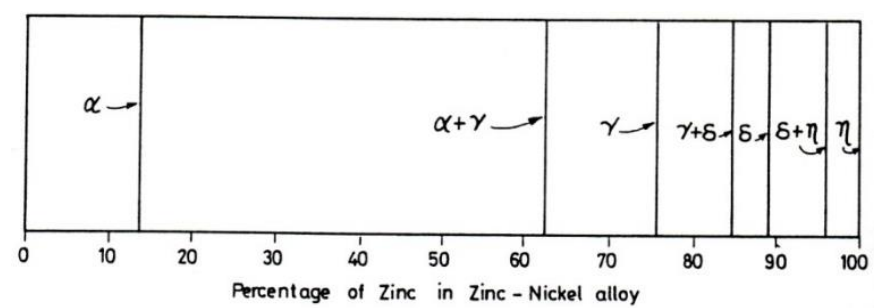

Fig. 5 Relationship between phase structure and percentage of zinc in the Zn-Ni alloy deposit

\subsection{Structure and Morphology}

The phase structure of electrodeposited $\mathrm{Zn}-\mathrm{Ni}$ alloy from an acid sulphate bath containing ethanolamines was studied by X-ray powder diffraction. Fig. 5 shows the relationship between the phase structure and the percentage of nickel in the alloy deposit. The phase diagram of $\mathrm{Zn}-\mathrm{Ni}$ alloy reveals the presence of intermetallic phases: $(\eta)$ Hexagonal, $(\delta)$ F.C.C, $(\gamma)$ B.C.C and $(\alpha)$ B.C.C. Low zinc containing alloy shows a solid solution of zinc in nickel, i.e., $\alpha$-phase, whereas zinc rich alloy deposits showed intermetallic phases: $\eta, \delta$ and $\gamma$. Thus, electrodeposited $\mathrm{Zn}-\mathrm{Ni}$ alloys have intermetallic phases over a wide range of composition: $\eta(89-100 \% \mathrm{Zn}), \gamma$ $(13.5-84.5 \% \mathrm{Zn}), \delta(75.5-89 \% \mathrm{Zn})$ and $\alpha(0-62.5 \% \mathrm{Zn})$. The surface morphology of Zn-Ni alloy deposits was examined under scanning electron microscope. Fig. 6 shows the morphology of $\mathrm{Zn}-\mathrm{Ni}$ alloy deposits obtained https://doi.org/10.30799/jaec.060.20060102 at $40 \mathrm{~A}_{\mathrm{dm}}^{-2}$ from an acid sulphate bath containing various ethanolamines. The morphology of $\mathrm{Zn}-\mathrm{Ni}$ alloy deposits shows uniform and finer grained structure.

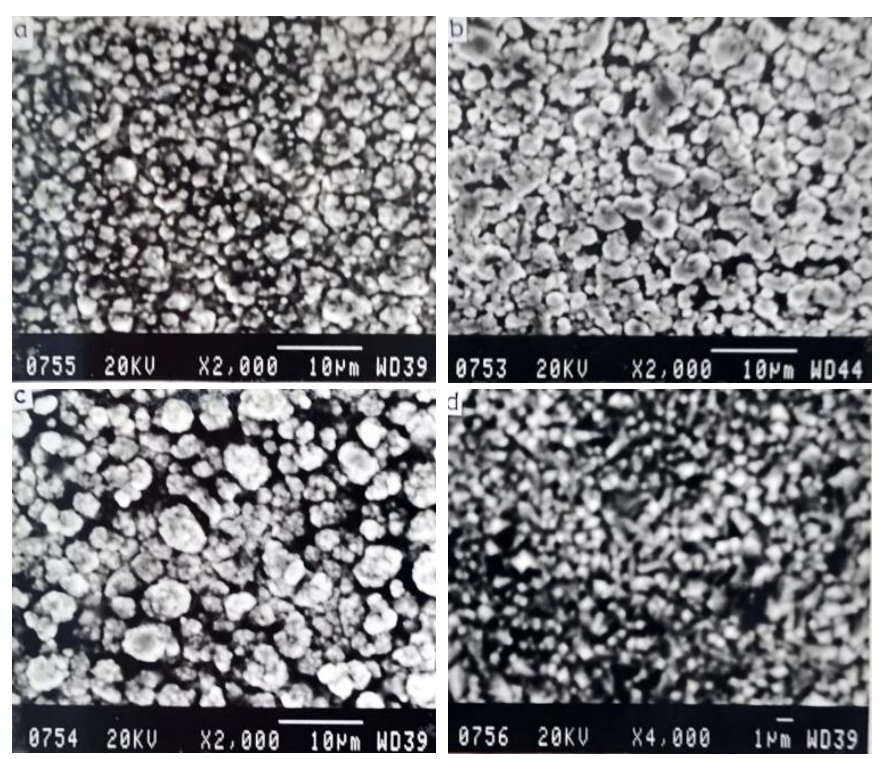

Fig. 6 scanning electron micrographs of $\mathrm{Zn}-\mathrm{Ni}$ alloy deposits obtained from an acid sulphate bath containing various ethanolamines. a. Bath with NA, cd $40 \mathrm{~A}^{-\mathrm{dm}^{-2}}$; b. Bath with MEA, cd 40 A.dm²; c. Bath with DEA, cd 40 A.dm $^{-2}$; d. Bath with TEA, cd 40 A.dm ${ }^{-2}$

\section{Conclusion}

Electrodeposition of $\mathrm{Zn}-\mathrm{Ni}$ alloy having $10-15 \% \mathrm{Ni}$ from an acid sulphate bath containing ethanolamines follows anomalous co-deposition. The deposition potential of alloy is less noble to both zinc and nickel deposition. A bath having high nickel content (50\%) produces an alloy with low nickel content (12\%). Increase in current density, temperature and stirring increases the percentage of nickel in the alloy deposit. With increase in thickness of the alloy deposit, the percentage of nickel increases, reaches a maximum and then decreases with further increase in thickness. The cathodic current efficiency is dependent on current density, temperature and stirring of the bath. Hardness of the alloy increases with increase in nickel content of the alloy, the phase structure of alloy deposit shows the presence of $\alpha, \eta, \delta$ and $\gamma$ phases. The morphology of $\mathrm{Zn}-\mathrm{Ni}$ alloy deposits shows uniform and finer grained structure.

\section{Acknowledgement}

The author, V. Narasimhamurthy thank the Chairman, Department of Metallurgy, Indian Institute of Science, Bangalore for SEM data and grateful to CSIR, New Delhi for the financial assistance.

\section{References}

[1] A. Brenner, Electrodeposition of alloys, Vols. I and II, Academic press, New York and London, 1963.

[2] M.M. Abou-Krisha, F.H. Assaf, A.A. Toghan, Electrodeposition of $\mathrm{Zn}-\mathrm{Ni}$ alloy from an acid sulfate bath, J. Sol. Stat. Elect. 11 (2007) 244-252.

[3] B.M. Praveen, T.V. Venkatesha, New brightener for Zn-Ni alloy plating from sulfate bath, J. Chem. Eng. Comm. 199(6) (2012) 812-822.

[4] M.J. Rahman, S.R. Sen, M. Moniruzzaman, K.M. Shorowordi, Morphology and properties of electrodeposited $\mathrm{Zn}-\mathrm{Ni}$ alloy coatings on mild steel, J. Mech. Eng. 40(1) (2009) 10-16.

[5] N. Lotfi, M. Aliofkhazraei, H. Rahmani, G. Barati Darband, Zinc-Nickel alloy electrodeposition: characterization, properties, multilayer's and composites, Prot. Metals Phy. Chem. Surf. 54 (2018) 1102-1140.

[6] Gabriella Roventi, Electrodeposition of nickel-zinc alloy from a sulfamate bath, Advan. Mats. 4 (2015) 21-26.

[7] V. Ravindran, V.S. Muralidharan, Electrodeposition of Zn-Ni alloy, J. Sci. Ind Res, 62 (2003) 718-722.

[8] S. Basavanna, Y. Arthoba Nayaka, Electrochemical studies of Zn-Ni alloy coatings from acid chloride bath, J. App. Elect. Chem. 39(10) (2009) 1975-1982.

[9] R.S. Bhat, S. Bekal, A.C. Hegde, Fabrication of Zn-Ni alloy coatings from acid chloride bath and its corrosion performance, Anal. Bioanal. Elect. Chem. 10(12) (2018) 1562-1573.

[10] M.G. Hussein, H. Ashassi-Sorkhabi, H.A.Y. Ghiasvand, Electrochemical studies of $\mathrm{Zn}-\mathrm{Ni}$ alloy coatings from non-cyanide alkaline bath containing tartrate as complexing agent, Sur. Coat. Tech. 202(13) (2008) 2897-2904. 
[11] Katarzyna Wykpis, Magdalena Popczyk, Antoni Budniok, Electrolytic deposition and corrosion resistance of $\mathrm{Zn}-\mathrm{Ni}$ coatings obtained from sulphatechloride bath, Bull. Mat. Sci. 34(4) (2011) 997-1001.

[12] Israel Rodriguez, G. Valentin, François Lapicque, Electrodeposition of zincnickel alloys from ammonia-containing baths, J. App. Elect. Chem. 29(9) (199) 1035-1044.

[13] Hiroaki Nakano, Shingo Arakawa, Satoshi Oue, Shigeo Kobayashi, Electrodeposition behavior of $\mathrm{Zn}-\mathrm{Ni}$ alloys from an alkaline zincate solution containing ethylenediamine, ISIJ Inter. 53(10) (2013) 1864-1870.

[14] S. Rajendran, S. Bharathi, T. Vasudevan, Electrodeposition of Zinc-Nickel alloy from a cyanide-free alkaline plating bath, Trans. IMF 78(3) (2017) 129-133.
[15] Zhongbao Feng, Qingyang Li, Jinqiu Zhang, Peixia Yang, Maozhong An, Electrochemical behaviors and properties of $\mathrm{Zn}-\mathrm{Ni}$ alloys obtained from alkaline non-cyanide bath using $5,5^{\prime}$--dimethylhydantoin as complexing agent, J. Elect. Chem. Soc. 162 (2015) D412-D422.

[16] S. Mohan, V. Ravindran, B. Subramanian, G. Saravanan, Electrodeposition of zinc-nickel alloy by pulse plating using non-cyanide bath, Trans. IMF 87(2) (2013) 85-89.

[17] S. Srinivasan, P.R. Thangavelu, K.N. Srinivasan, M Selvam, Zn-Ni alloy deposit for cadmium replacement applications, IJESRT 2(10) (2013) 3041-3046.

[18] K. Higashi, H. Fukushima, T. Urokawa, T. Adaniya, K. Matsudo, Mechanism of the electrodeposition of zinc alloys containing a small amount of cobalt, J. Elect. Chem. Soc. 128 (1981) 2081-2084. 